\title{
Hydrodynamic Aspects of Staggered Spoilers fitted Subsea Pipelines
}

\author{
Ahmed El Shafei ${ }^{1}$, Mohamed A. Kotb ${ }^{2}$, Amr A. Hassan ${ }^{2}$ and Khalid M. Saqr ${ }^{1}$ \\ [1] Department of Mechanical Engineering, College of Engineering and Technology \\ Arab Academy for Science, Technology and Maritime Transport, Abu Kir P.O. Box 1029,Alexandria - EGYPT \\ [2] Department of Marine Engineering, College of Engineering and Technology \\ Arab Academy for Science, Technology and Maritime Transport, Abu Kir P.O. Box 1029, Alexandria-EGYPT
}

\begin{abstract}
Subsea pipelines are affected with many surrounding challenges. One of these challenges is the current-induced hydrodynamic stresses which affect the pipeline throughout its life span. Therefore, several methods have been suggested to reduce these stresses and hence protect the pipe. The aim of this paper is to investigate the effect of one of the protection methods; that is fitting the pipe with staggered spoilers along its length using computational fluid dynamics. A computational model based on Navies-Stokes for a single phase flow was developed to simulate the flow around the pipeline. Five turbulence models are used in the numerical investigation and their results are validated against the experimental data of a fully exposed pipeline resting on a plane boundary under various flow conditions. Comparison between flow field characteristics around the pipe with and without spoilers are conducted and discussed.
\end{abstract}

Keywords: Submarine pipeline, spoiler, hydrodynamic forces, turbulence models

\subsection{INTRODUCTION}

Submarine pipeline is one of the most important oil transportation components; however, they are surrounded by sea environment which has a significant effect on its operation. Thus, protection should be provided against these environmental loads which may result in excessive hydrodynamic stresses. These stresses play a significant role in assessing pipeline failure that can lead to severe environmental hazards.

\subsection{Subsea pipeline protection methods}

In order to protect the pipelines from possible damage caused by excessive hydrodynamic forces (lift, drag and inertia) arising from waves and currents or the human activities of dragging/dropped anchors, pipelines must be buried to a certain depth so that it is below the seabed. But the cost for artificial trenching and refilling is high, and these costs form a large proportion of the total pipeline project budget. So there could be significant cost savings in the pipeline industry, if the self-burial process could be exploited. Recently published investigations have shown that a submarine pipeline fitted with a spoiler can bury itself (L.Yang, 2012). The effects of these spoilers, in addition to their configuration arrangements on the pipes self-burial characteristic is not quantitively explained. The changes on the flow field around subsea pipelines produced due to these spoilers need to be investigated. Mike P Edfeldtprovides a new method for promoting selfburial and stabilizing pipelinesin the bottom of sea bed known as staggered spoilers with certain conditions concerning that the spoilers being radially spaced from $10^{\circ}-30^{\circ}$ and longitudinally spaced from $0.1 \mathrm{~m}$ to $1.5 \mathrm{~m}$ as shown in figure (1) below and this is considered the aspect in which this study will revolve.

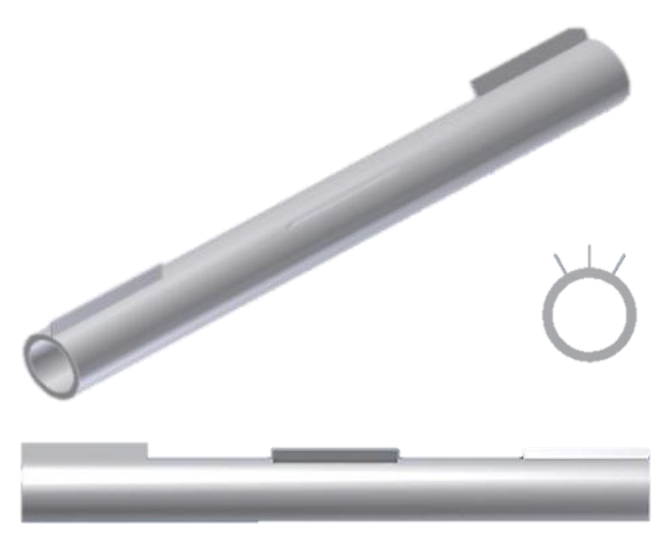

Figure 1.3D, side and elevational views of a pipeline with staggered spoilers

\subsection{Research objectives and methodology}

The aim of this paper is to investigate the effect of staggered spoiler protection configuration on the hydrodynamic stress on pipeline using CFD. It was noticed that most published researches in the past decades were carried out for studying flow over a subsea pipeline 
are $2 \mathrm{D}$ based, it is obvious that some inherent characteristics/features of the flow can only be simulated by a 3D model; especially as the scour process and vortex regimes are different in each dimension. A 3D numerical simulation using 505196 grid cell and second order accuracy has been conducted and compared to the experimental work done by (Bearman 1978) at Reynolds number of $4.5 \times 10^{5}$ in order to validate the proposed CFD model, and select the optimum turbulence model that is capable of simulating the turbulent current around the pipeline with minimum modeling error following the (AIAA, 1998) recommendations.

\subsection{LITERATURE REVIEW}

In this section, a brief review about previous works done by other researchers, which has been used as basic background for this study, will be discussed and concluded by a tabulated summary of recent relevant numerical simulation studies for subsea pipeline hydrodynamics.

Table 1. Summary of numerical studies on subsea pipelines

\begin{tabular}{|c|c|c|c|c|}
\hline Reference & Problem definition & $\begin{array}{c}\text { Numerical } \\
\text { Formulation }\end{array}$ & $\begin{array}{c}\text { Reynolds } \\
\text { number }\end{array}$ & $\begin{array}{c}\text { Turbulence } \\
\text { model }\end{array}$ \\
\hline Hatipoglu and Avci (2003) & $\begin{array}{l}\text { Flow around surface mounted or partially } \\
\text { buried pipe in a steady current }\end{array}$ & $\begin{array}{ll}\bullet & \text { Finite volume } \\
- & \text { Two dimensional domain } \\
& (2-\mathrm{D}) \\
-\quad & \text { Non-uniform structured grid }\end{array}$ & $\begin{array}{l}1.3 \times 10^{4} \sim \\
2.6 \times 10^{4}\end{array}$ & \\
\hline Liang and Cheng (2005) & $\begin{array}{l}\text { Scour below offshore pipelines in steady } \\
\text { currents }\end{array}$ & \multirow{3}{*}{$\begin{array}{ll}\text { - } & \text { Finite difference } \\
\text { - } & \text { Two dimensional domain } \\
& (2-\mathrm{D}) \\
\text { - } & \text { Non-uniform structured grid }\end{array}$} & 7000 & $\begin{array}{c}\mathrm{k}-\varepsilon \\
\mathrm{k}-\omega \\
(\text { Standard } \\
\text { and Wilcox) }\end{array}$ \\
\hline Zhang and Cheng (2008) & $\begin{array}{l}\text { Scour below offshore pipeline under wave } \\
\text { action. }\end{array}$ & & $\begin{array}{l}1000 \sim \\
100,000\end{array}$ & $\mathrm{k}-\omega$ \\
\hline Zhao and Wang (2009) & Flow around submarine pipe with a spoiler & & $\begin{array}{c}\text { Not } \\
\text { reported }\end{array}$ & $\mathrm{k}-\varepsilon$ \\
\hline Zakeri et al (2010) & $\begin{array}{l}\text { Seabed debris flow impact on suspended } \\
\text { and laid-on-seafloor pipelines }\end{array}$ & $\begin{array}{ll}\text { - } & \text { Finite volume } \\
\text { - } & \text { Three dimensional domain } \\
& (3-\mathrm{D}) \\
\text { - } & \text { Non-uniform unstructured } \\
\text { grid }\end{array}$ & 150 & \\
\hline Hongwei An (2011) & $\begin{array}{l}\text { Flow around a partially buried pipe at } \\
\text { combined oscillatory flow and steady } \\
\text { current }\end{array}$ & $\begin{array}{ll}\text { - } & \text { Finite element } \\
\text { Two dimensional domain } \\
\text { (2-D) } \\
\text { - } \quad \text { Structured four-node } \\
\text { quadrilateral elements }\end{array}$ & $3 \times 10^{5}$ & $\mathrm{k}-\omega$ \\
\hline $\begin{array}{l}\text { Kazeminezhad and } \\
\text { Yeganeh Bakhtiary (2011) }\end{array}$ & $\begin{array}{l}\text { Two-phase simulation of seawater and } \\
\text { seabed scour around submarine pipeline }\end{array}$ & \multirow{4}{*}{$\begin{array}{l}\text { - } \quad \text { Finite volume } \\
\text { Three dimensional domain } \\
\text { (3-D) } \\
\text { Non-uniform unstructured } \\
\text { grid }\end{array}$} & $\begin{array}{c}\text { Not } \\
\text { reported }\end{array}$ & $\mathrm{k}-\varepsilon$ \\
\hline Chen and Su (2012) & $\begin{array}{l}\text { Simulation of steady flow around a cylinder } \\
\text { placed near to, but not tangent to, a plane } \\
\text { boundary. }\end{array}$ & & $\begin{array}{l}\text { From } 930 \\
\text { to } 2570\end{array}$ & $k-\omega$ \\
\hline Zhu et al. (2013) & $\begin{array}{l}\text { Flow and seabed scour around subsea } \\
\text { pipeline with a vertical upper spoiler }\end{array}$ & & $5.07 \times 10^{4}$ & SST k- $\omega$ \\
\hline B.E. Larsen (2016) & $\begin{array}{l}\text { Simulation of Wave-Plus-Current Scour } \\
\text { beneath Submarine Pipelines }\end{array}$ & & $\begin{array}{l}\text { Not } \\
\text { reported }\end{array}$ & $\mathrm{k}-\omega$ \\
\hline
\end{tabular}

Table 1 summarizes references with most significant contribution to subsea pipelines.

Research on Table (1) above mostly is concerned with predictions of the flow around pipeline and its resulting hydrodynamic stresses on the pipeline wall, in addition to the characterization of the seabed scour phenomena beneath the pipeline. The two-dimensional approximation of the problem is widely adopted in the state-of-the-art literature; however. For the design of subsea pipelines, three-dimensional models are computationally more efficient than 2D models especially in terms of physical insight to the flow structure and consequentially, a better prediction of the seabed changes. It is also clear from the research reviewed that the finite volume method is the most common approach for the problem in hand.

\subsection{MATHEMATICAL MODEL}

In this study, the flow field around a pipeline laid on a plane is modeled using the incompressible threedimensional (3D) Reynolds-averaged continuity and Navier-Stokes equations. 


$$
\begin{gathered}
\frac{\partial u}{\partial x}+\frac{\partial v}{\partial y}+\frac{\partial w}{\partial z}=0(1) \\
\rho u_{j} \frac{\partial u_{i}}{\partial x_{j}}+\rho \frac{\partial u_{i}}{\partial t}=\rho K_{i}-\frac{\partial p}{\partial x_{i}}+\mu \frac{\partial^{2} u_{i}}{\partial x_{j} \partial x_{j}}+ \\
\frac{\partial}{\partial x_{j}}\left(-\rho \overline{u_{\imath}^{\prime} u_{j}^{\prime}}\right)(2)
\end{gathered}
$$

In equations (1) and (2), $\mathrm{u}_{\mathrm{i}}$ represent the velocity components in $\mathrm{x}_{\mathrm{i}}$ direction; $\rho$ is the density of fluid; $K$ is the body force due to gravity; $\mathrm{p}$ is the pressure; $\mu$ is the dynamic viscosity; $-\rho \overline{u_{1}^{\prime} u_{j}^{\prime}}$ is the Reynolds stress tensor, $\mathrm{u}_{\mathrm{i}}^{\prime}$ and $\mathrm{u}_{\mathrm{j}}^{\prime}$ are the horizontal and vertical velocity fluctuations, respectively. Theturbulent stresses in equation (2) can be obtained from the constitutive equation defined as in the following.

$$
-\rho \overline{u_{\imath}^{\prime} u_{\jmath}^{\prime}}=\eta\left(\frac{\partial \mathrm{u}_{\mathrm{i}}}{\partial \mathrm{x}_{\mathrm{j}}}+\frac{\partial \mathrm{u}_{\mathrm{j}}}{\partial \mathrm{x}_{\mathrm{i}}}\right)-\frac{2}{3} \rho k \delta i j(3)
$$

Where $k$ is the turbulence kinetic energy, $\delta_{\mathrm{ij}}$ is the Kronecker delta, and $\eta$ is the turbulent or eddy viscosity coefficient. Various turbulence closure models in computational fluid dynamics (CFD) simulations have been used to determine the turbulent viscosity, $\eta$, in equation (3). In the present numerical simulation, $k-\varepsilon$ (Standard and Realizable), $k-\omega$ (Standard and SST), and Reynolds stress model (RSM) turbulence closure models were employed. Standard $k-\varepsilon$ turbulence closure model is a well-known two-equation turbulence model which expresses the turbulence viscosity in terms of kinetic energy, $k$, and its dissipation rate, $\varepsilon$. Another two-equation turbulence closure model is the $k-\omega$ model which is less commonly used compared to the $k-\varepsilon$ model; $k-\omega$ turbulence closure model was reported to have the advantages near the walls to predict the turbulence length scale $\left(\ell \sim k^{1 / 2} / \omega\right)$ accurately in the presence of adverse pressure gradient boundary layer flow. To combine the advantages of $k-\varepsilon$ and $k-\omega$ models, Menter (AIAA J 1994) presented the SST turbulence closure model that uses a blending function, $F_{l}$, which ensures smooth transition between the $k-\omega$ model near the wall regions and $k-\varepsilon$ away from the wall. Thus, SST model coefficients reduce to the $k-\omega$ and $k-\varepsilon$ model coefficients in their respective regions.

\subsection{NUMERICAL METHOD AND SOLUTION DOMAIN}

\subsection{Numerical method details}

The numerical solution of the Reynolds-averaged continuity and Navier-Stokes equations (equations (1) and (2)) are obtained using ANSYS FLUENT CFD code based on finite element methods. In the finite element discretization, the conservation forms of equations (1) and (2) were used. Therefore a transferable fluid property, $\phi$ is defined per unit mass in a unit control volume as.

$$
\frac{\partial(\rho \phi)}{\partial t}+\operatorname{div}(\rho \phi \overrightarrow{\mathrm{V}})=\operatorname{div}\left(\Gamma_{\phi} \operatorname{grad} \phi\right)+S_{\phi}(4)
$$

In equation (4), $\vec{V}, \Gamma_{\phi}$, and $S_{\phi}$ are the velocity vector, generalized diffusion coefficient, and generalized source term, respectively. The value of the fluid property " $\phi$ " is 1 for the conservation of mass, and it is $\vec{V}$ for the conservation of momentum.

\subsection{Solution domain and boundary conditions}

In this study, a circular cylinder with a diameter of (D) and a height of $(0.25 \mathrm{D})$ spoiler is centered in the bottom of a 3D rectangular domain. The domain is (24D) length, (24D) width and (5D) height. The cylinder is $0.01 \mathrm{D}$ immersed in the bottom of the domain for a good quality of the computational mesh around the pipeline. , as shown in Figure 2. Velocity was specified as zero, known as noslip boundary condition, on the lower boundary and cylinder surface. The inlet condition has inlet velocity of $\mathrm{u}_{\mathrm{o}}=0.096 \mathrm{~m} / \mathrm{s}$ while the outlet boundary of the solution domain set as a constant pressure.

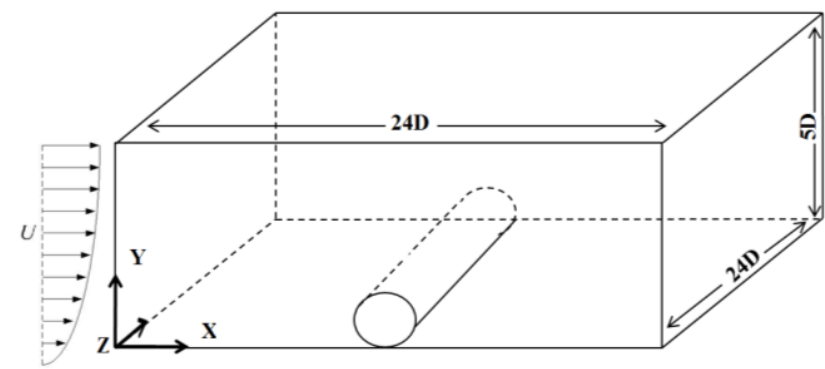

Figure 2. Schematic diagram of the computational domain and boundary conditions

\subsubsection{Computational meshing}

Non-uniform unstructured triangular meshes were used to discretize the computational domain for all cases. However, finer meshes were used near the lower boundary and the cylinder surface, where high magnitude vortices and high-gradient velocity distributions are created due to wall friction so that the fine mesh around the cylinder can accelerate the solution convergence rate avoiding the issues of solution divergence and errors in this critical area. Taking this fact into account, the computational domain was divided into number of subdomains in which different mesh densities of either uniform or compressed meshes were used. The mesh structures for staggered case are shown in Figure 3.

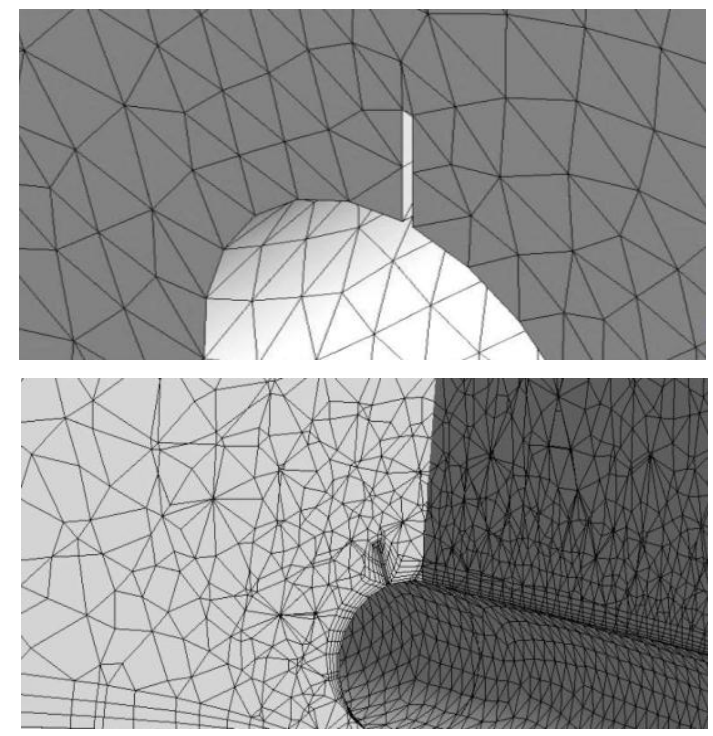

Figure 3.3D mesh structure of a staggered spoiler on a pipe 


\subsection{NUMERICAL RESULTS}

\subsection{Verification and validation of the CFD model}

In order to ensure that the model produces results that are consistent with the actual flow physics, a validation study was performed. A numerical simulation using 505196 grid cell was solved five times, each with a different turbulence model. The pressure coefficient on the pipe wall predicted by these models was compared to the benchmarking experiments of (Bearman and Zdravkovich, 1978) as shown in figure 4 . The results of the curves have the same trend which proves that the numerical model matches the experimental results where SST model gave almost the best result as it is the closest pattern to experimental throughout the whole graph compared with standard and realizable $k-\varepsilon$, standard $k-\omega$ and RSM models which show a divergent trend either throughout the middle section or at the beginning and ending of the graph this is because the SST model applies the standard $k-\omega$ near to wall and standard $k-\varepsilon$ in the rest of the flow, thus both are based on the least convergence time.

Table 2 shows the results of $k-\varepsilon$ (Standard and Realizable) models performed poorly in this type of flow. The SST $k-\omega$ obtained the best result among the used turbulence models processed by the RSM model, but SST turbulence model have the least deviation from the experimental data. The error of both $k-\varepsilon$ models is approximately twice that of both $k-\omega$ (Standard and SST) and RSM models. Based on the validation results it is confirmed that the numerical model suitable to solve the present problem.

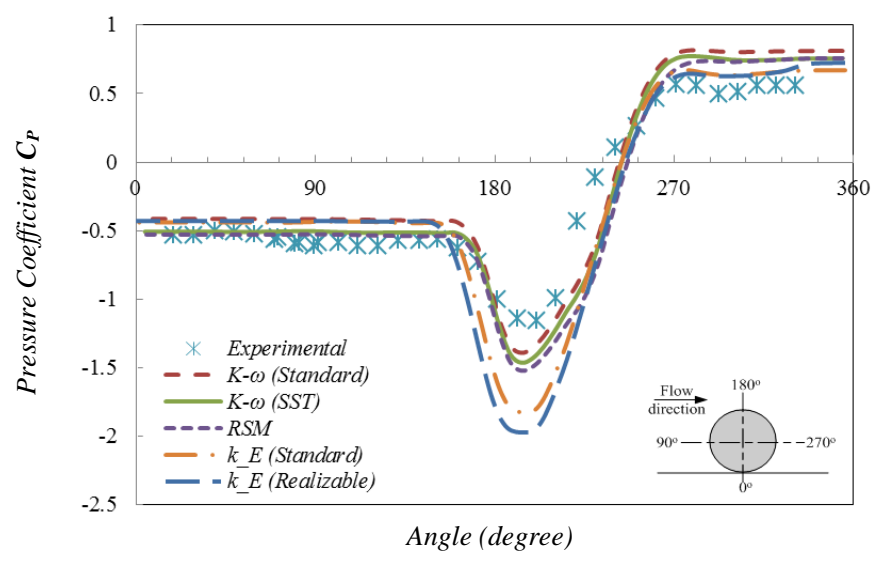

Figure 4.Comparison between experimental measurements of (Bearman and Zdravkovich, 1978) and pressure coefficient $\left(\mathrm{C}_{\mathrm{p}}\right)$ obtained from different turbulence models.

Table 2.Turbulence models error quantification

\begin{tabular}{|c|c|c|c|c|c|c|}
\hline \multirow{2}{*}{$\begin{array}{c}\text { Turbulence } \\
\text { model }\end{array}$} & \multicolumn{2}{|c|}{$\begin{array}{c}\text { Location on } \\
\text { cylinder wall }\end{array}$} & \multicolumn{2}{|c|}{$\begin{array}{c}\text { Computed } \\
\text { pressure } \\
\text { coefficient }\left(\mathbf{C}_{\mathrm{p}}\right)\end{array}$} & \multicolumn{2}{|c|}{ Max. error } \\
\cline { 2 - 7 } & $\boldsymbol{a}$ & $\boldsymbol{b}$ & $\boldsymbol{a}$ & $\boldsymbol{b}$ & $\boldsymbol{a}$ & $\boldsymbol{b}$ \\
\hline $\begin{array}{c}\text { Standard } \\
\mathrm{k}-\varepsilon\end{array}$ & $152^{\circ}$ & $215^{\circ}$ & -1.32 & -0.446 & $32 \%$ & $21 \%$ \\
\hline
\end{tabular}

\begin{tabular}{|c|l|l|l|l|l|l|}
\hline $\begin{array}{c}\text { Realizable } \\
\mathrm{k}-\varepsilon\end{array}$ & $152^{\circ}$ & $215^{\circ}$ & -1.45 & -0.479 & $45 \%$ & $15 \%$ \\
\hline $\begin{array}{c}\text { Standard } \\
\mathrm{k}-\omega\end{array}$ & $152^{\circ}$ & $215^{\circ}$ & -1.02 & -0.432 & $2 \%$ & $24 \%$ \\
\hline SST k- $\omega$ & $152^{\circ}$ & $215^{\circ}$ & -1.10 & -0.517 & $10 \%$ & $9 \%$ \\
\hline $\mathrm{RSM}$ & $152^{\circ}$ & $215^{\circ}$ & -1.19 & -0.538 & $19 \%$ & $5 \%$ \\
\hline
\end{tabular}

\subsection{RESULTS \& DISCUSSION}

\subsection{Pressure coefficient acting on the pipe wall}

Pressure coefficient on the pipeline as well as the associated flow filed will be reported in the following section. The pressure coefficient can be expressed as:

$$
C_{P}=\frac{P-P_{\infty}}{\frac{1}{2} \rho U^{2}}
$$

Where $\mathrm{P}$ is the local static pressure, $\mathrm{P}_{\infty}$ is the free stream static pressure, $\rho$ is the fluid density, and $U$ is the global velocity magnitude of the current.

The utmost condition for a subsea pipeline is to have a uniform distribution of pressure coefficient along its wall. It is also generally favorable to change values of the pressure coefficient along the pipe wall while maintaining its sign. It is also noted that the pipeline is subjected to lift force if $\mathrm{C}_{\mathrm{P}}$ has negative values on the upper half of the pipe and positive values near the seabed. In figures (5 $11)$, the pressure coefficient results on a pipeline fitted with staggered spoiler with radial spacing $10^{\circ}, 20^{\circ}$, and $30^{\circ}$ and longitudinal spacing for $0.1 \mathrm{~m}$ and 1.5 meter are given. The pressure coefficients will be reported at two stations. The first at downstream of one of the fitted spoilers at the mid distance between two spoilers, while the other station crossing a spoiler. These results are compared to the bare (unprotected) pipe case. The results for the large spacing $(1.5 \mathrm{~m})$ looks very much in trend as the unprotected pipe due to decay of upstream flow of the forward spoiler. The spoiler effect is clearly manifested at the small spacing case; very much reduced suction at the pipe top position $\left(180^{\circ}\right)$ compared to bare pipe at the same position. These results contribute to much less pipe uplift.

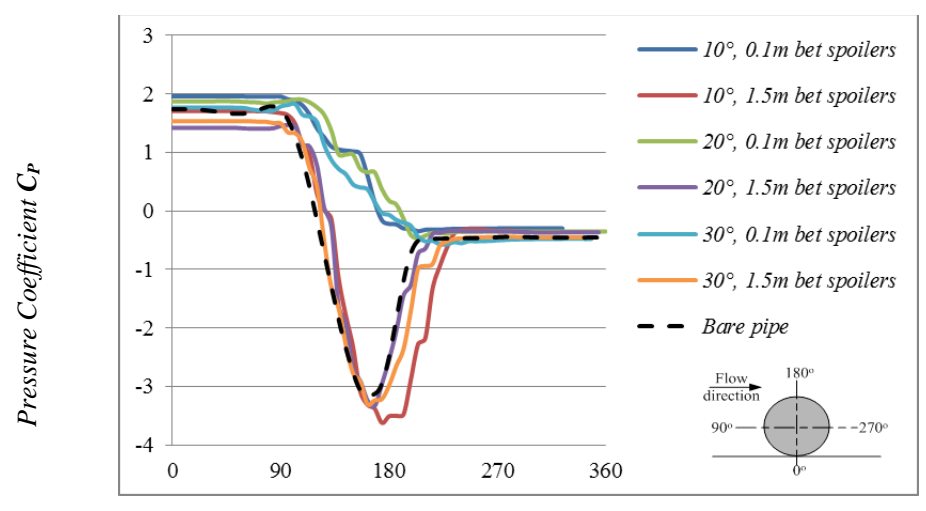

Figure 5.Pressure coeffigicientsofor $10^{\circ}, 20^{\circ}$ and $30^{\circ}$ staggered spoilers at middle of spacing

As shown in figure (5) it can be seen that positions at middle of spacing between spoilers for $10^{\circ}, 20^{\circ}$ and $30^{\circ}$ 
radial spacing $C_{P}$ has a negative value at pipe from $90^{\circ}$ to $180^{\circ}$ and positive value at sea bed from $0^{\circ}$ to $90^{\circ}$ and this means that the pipe subjected to a lifting force. From $180^{\circ}$ to $270^{\circ}$ pressure increases as the flow goes farther downstream which illustrate the decrease in downstream velocity while from $270^{\circ}$ to $360^{\circ}$ which is considered constant pressure area, a flow separation occurs and a flat $\mathrm{C}_{\mathrm{P}}$ distribution will be exhibited. For $10^{\circ}$ staggered at center of spoiler (Figure 6), from $0^{\circ}$ to $90^{\circ}$ the curves show that $C_{P}$ value is positive and from $90^{\circ}-180^{\circ}$ reserving a positive value which means the absence of lifting force causing stability of pipe on seabed without any movement; after $180^{\circ}$ at center of spoiler an early separation happen resulted from presence of spoiler, then pressure decreases from +ve region to $-v e$ region. The presence of a dip in $C_{P}$ pressure is also noticed due to the physical existence of upstream spoiler. As shown in Figure 7, for case of $20^{\circ}$ staggered there wasn't a noticed change from $0^{\circ}$ to $90^{\circ}$ while from $90^{\circ}$ to $180^{\circ}$ although it show $+v e \mathrm{C}_{\mathrm{P}}$ its less than that of $10^{\circ}$ showing an increase in lifting force. While for case of $30^{\circ}$ (Figure 8), it's been observed that the increase in radial spacing $\left(10^{\circ}-30^{\circ}\right)$ leads to increase in fluctuation with an excessive increase shown at $30^{\circ}$ causing a repetitive occurrence in negative region.

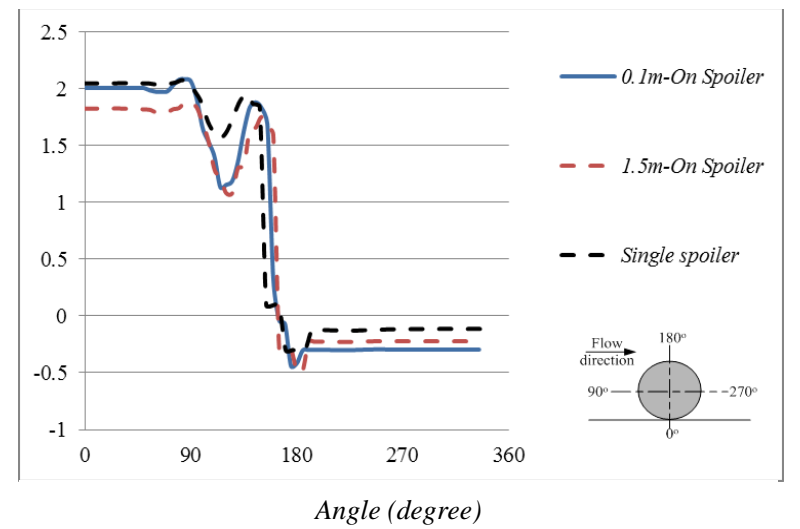

Figure 6.Pressure coefficients for $10^{\circ}$ staggered spoilers at center of spoiler

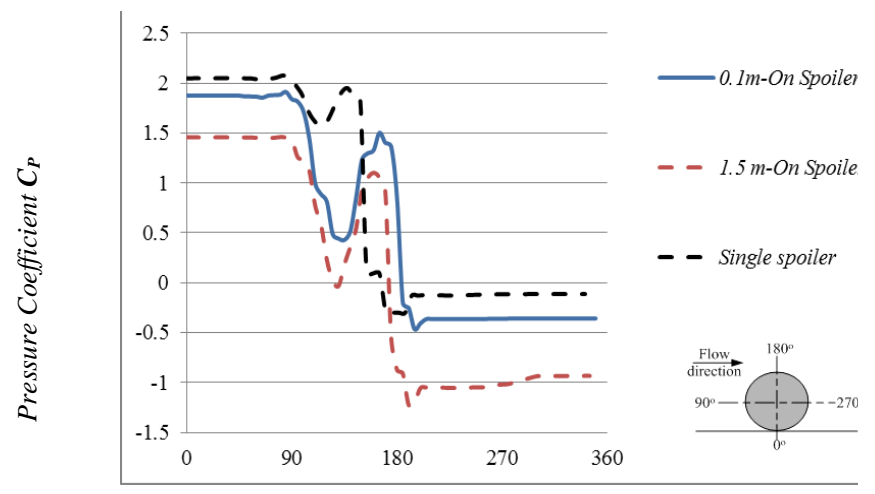

Figure 7.Pressure Anglef(degree) corficients $20^{\circ}$ staggered spoilers at center of spoiler

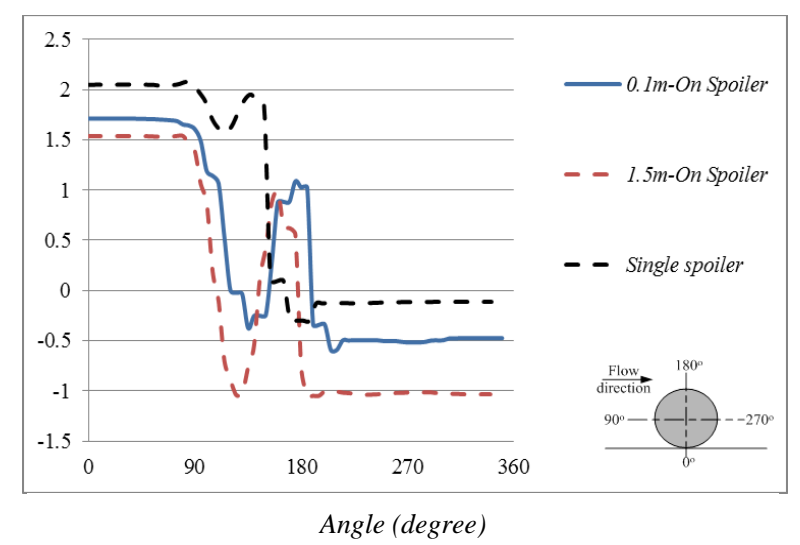

Figure 8.Pressure coefficients for $30^{\circ}$ staggered spoilers at center of spoiler

After detecting that $10^{\circ}$ radial spacing is the best solution so there is an inclination to study the increase in spoiler's height from $0.25 \mathrm{D}$ to $0.5 \mathrm{D}$. According to figure (9)by increasing spoiler's height the fluctuation decreased and the curves seem to be more stable which considered an improvement regarding middle of spacing between spoilers. In figure 10 at the center of spoiler it is deducted that increasing the spoiler height benefit and improve the results therefore spoiler height of $0.5 \mathrm{D}$ is considered the best condition. Noting that the curve slope at the beginning $\left(0^{\circ}-180^{\circ}\right)$ is lifted compared with $0.25 \mathrm{D}$ spoiler height curve at $10^{\circ}$ staggered spoiler meaning more stability is established and uniform distribution of $C_{P}$.

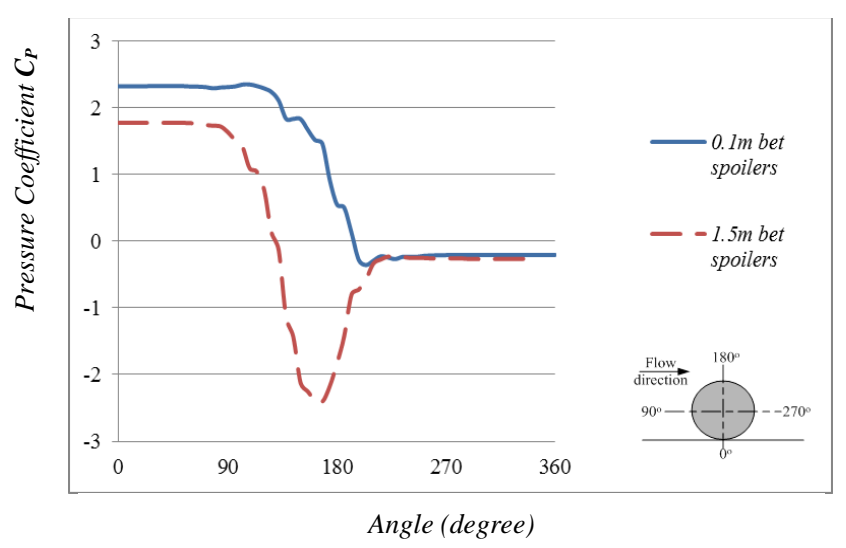

Figure 9. $\mathrm{C}_{\mathrm{P}}$ for $10^{\circ}$ staggered spoilers with $0.5 \mathrm{D}$ at middle of spacing

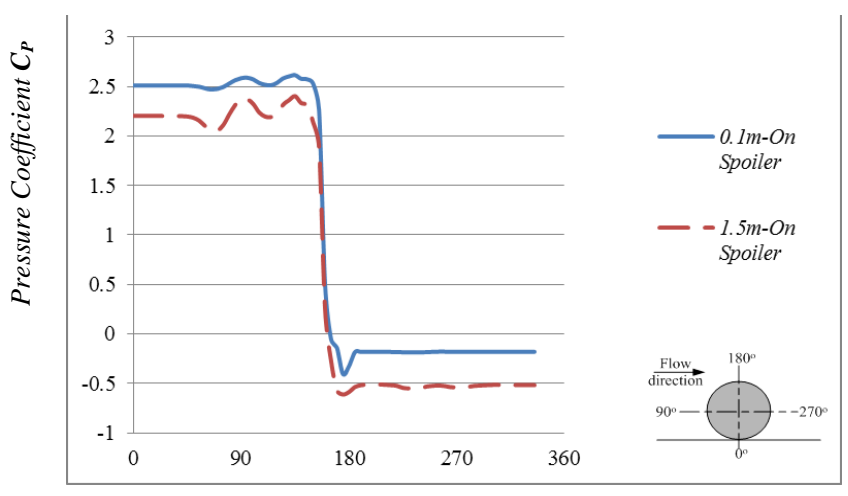

Angle (degree)

Figure 10.Pressure coefficients for $10^{\circ}$ staggered spoilers with $0.5 \mathrm{D}$ at center of spoiler 
By studying $C_{P}$ between spacing and at center of spoilers, the study revolved around center of first spoiler at an angle of $0^{\circ}$ over dead center and now a further study of the center of second and third spoilers at angles of $+\alpha^{\circ}$,$\alpha^{\circ}$ from on top of dead center and a conclusion was reached that curves of $\mathrm{C}_{\mathrm{P}}$ of first and second spoilers $\left(0^{\circ},+\alpha^{\circ}\right)$ have symmetrical behavior for all cases but $C_{P}$ at third spoiler $\left(-\alpha^{\circ}\right)$ has less fluctuation and the pressure drop in the beginning of the curves disappears in this case. At the third spoiler the least stresses were faced by the pipe as a result of early flow collision leading to decreased subjecting of stresses upon the rest of pipe behind the spoiler, while the other two cases the pipe was exposed partially to the flow before reaching spoiler causing a drop in $\mathrm{C}_{\mathrm{P}}$.

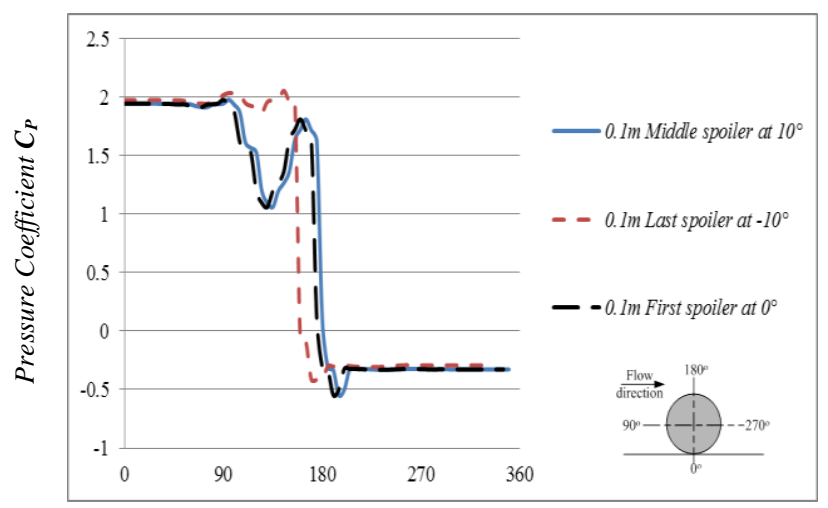

Angle (degree)

Figure 11. $C_{P}$ for $10^{\circ}$ staggered spoilers with $0.1 \mathrm{~m}$ spacing at center of spoiler at different locations

\section{2}

\section{Flow structure around the pipe}

By studying the streamline velocity, the separation occurred earlier and downstream vortices increased compared to bare pipe case. As longitudinal spacing increases from $0.1 \mathrm{~m}$ to $1.5 \mathrm{~m}$, velocity value decreases and vortices will decrease as well, as shown in figure (12) and with increase in radial spacing from $10^{\circ}$ to $30^{\circ}$ an early separation will occur due to early spoiler flow meeting (figure 13).As spoiler height increases to $0.5 \mathrm{D}$ the downstream vortices will increase in size but not in magnitude compared to $0.25 \mathrm{D}$ (figure 14) and as shown from velocity contour for $20^{\circ}$ staggered spoiler the maximum velocity reached in downstream and the stagnation point exist at the spoiler edge (figure 15 and 16).
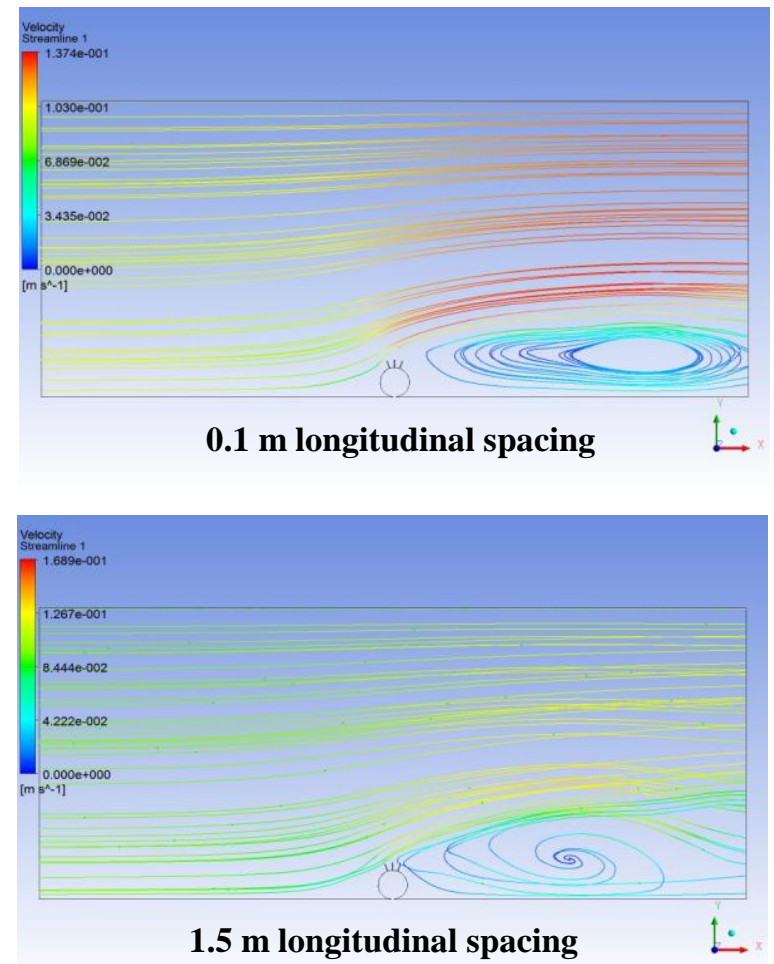

Figure 12.Streamlines for $20^{\circ}$ staggered spoiler with $0.25 \mathrm{D}$ spoiler height $\&$ different longitudinal spacing $(0.1-1.5 \mathrm{~m})$

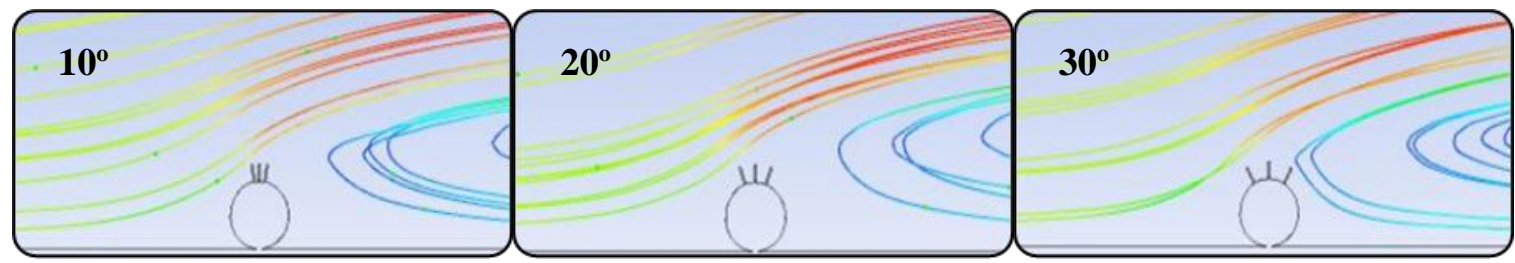

Figure 13.Different flow separation patterns for different radial spacing $\left(10^{\circ}-30^{\circ}\right)$ of $0.25 \mathrm{D}$ spoiler height

a.

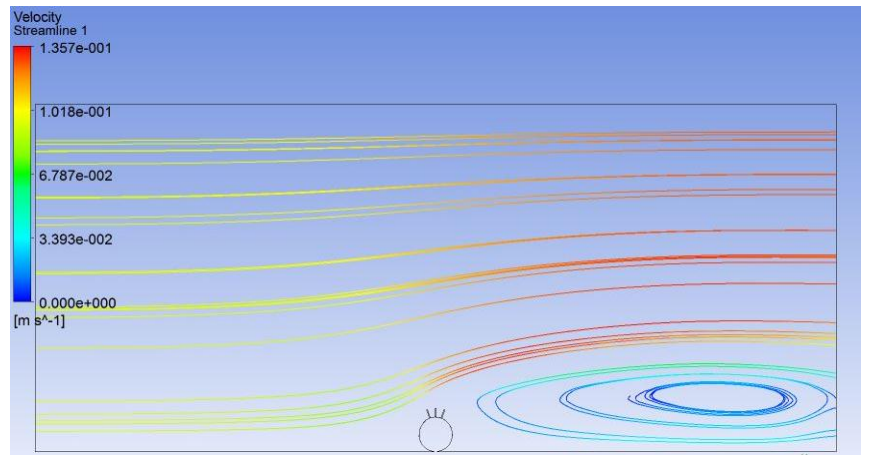

b.

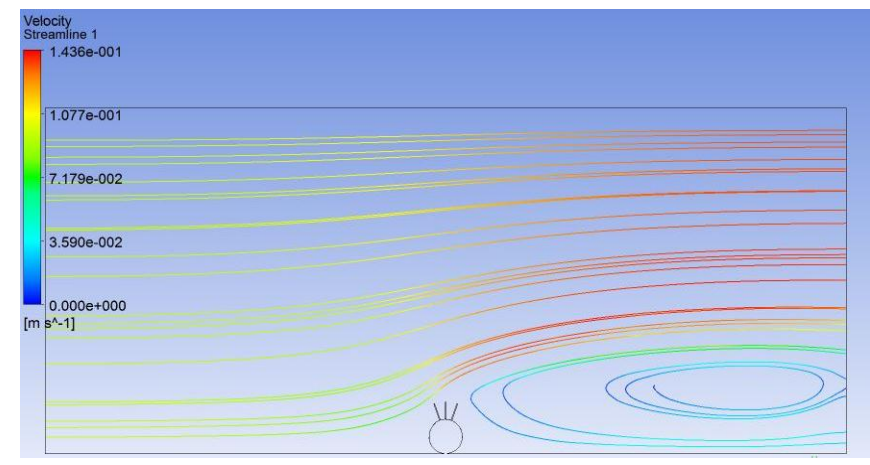

Figure 14.Streamlines for $20^{\circ}$ staggered spoiler of heights (a) $0.25 \mathrm{D}$ and(b) $0.5 \mathrm{D}$ 


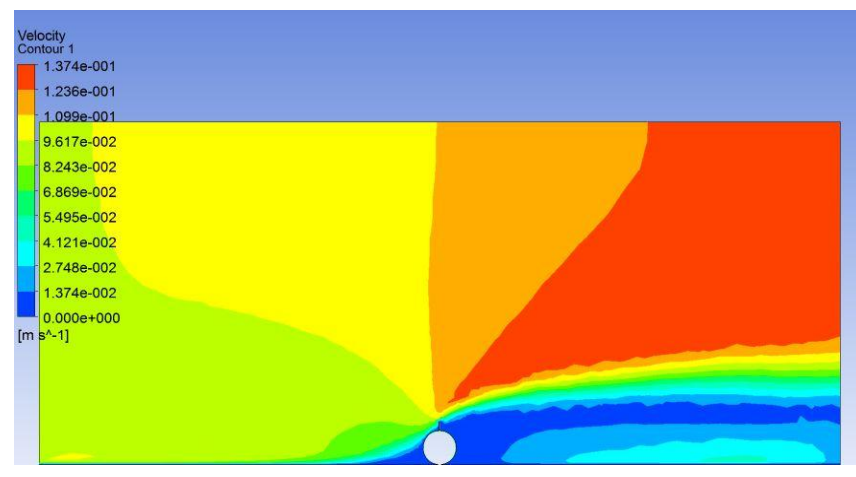

Figure 15.Velocity contour for $20^{\circ}$ staggered with $0.25 \mathrm{D} \& 0.1 \mathrm{~m}$ spacing

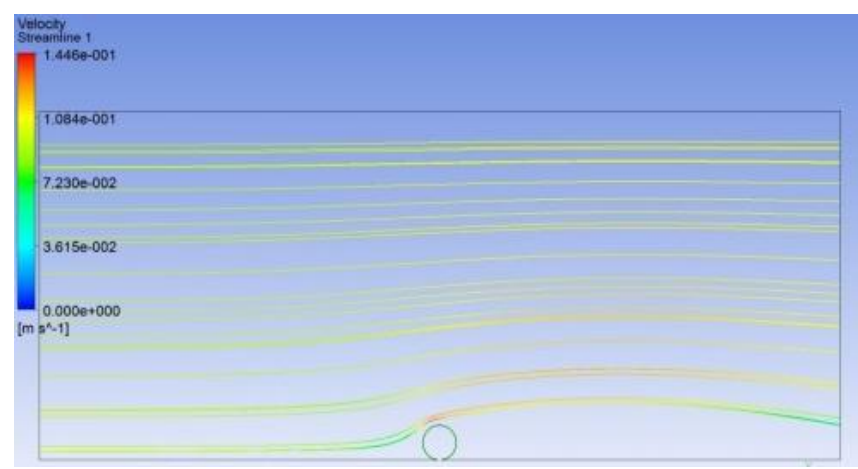

Figure 17.Streamlines for bare pipe

\subsection{Forces acting on studied cases}

Pressure distributions on the spoilers fitted pipes with different configurations are integrated to yield lift and drag forces acting on the pipeline. These are given on figures (19 and 20).From these figures, it is clearly shown

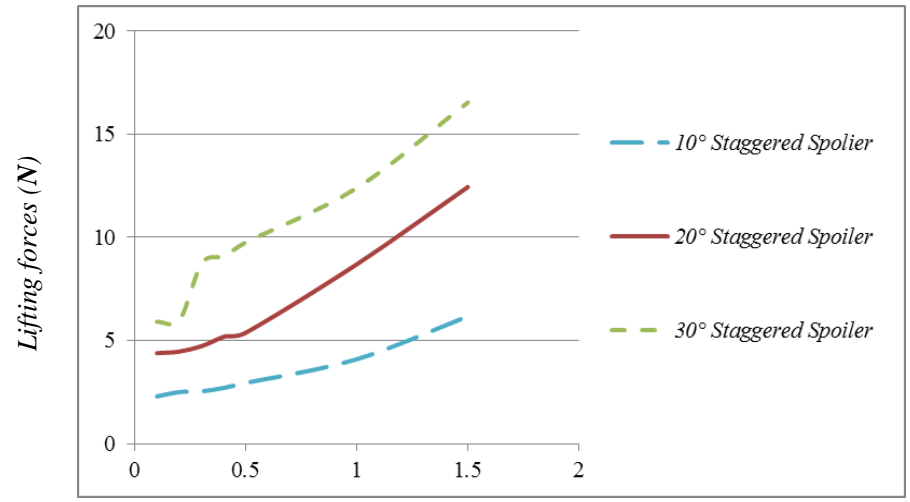

Longitudinal spacing ( $\boldsymbol{m})$

Figure 19.Graph of lifting forces as a function of spoiler's angles

\subsection{CONCLUSIONS \& RECOMMENDATIONS}

The main objective of this study is to examine and investigate how the proposed spoilers can be an effective way for protecting pipeline against hydrodynamic stresses by

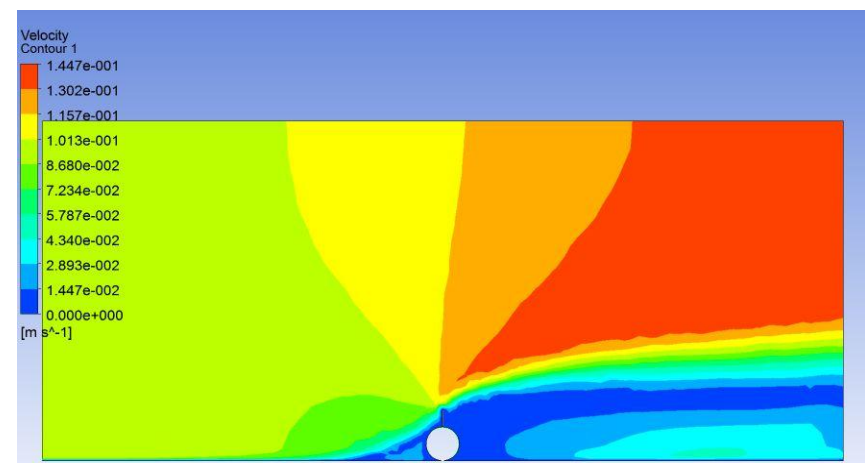

Figure 16. Velocity contour for $20^{\circ}$ staggered with $0.5 \mathrm{D}$ $\& 0.1 \mathrm{~m}$ spacing

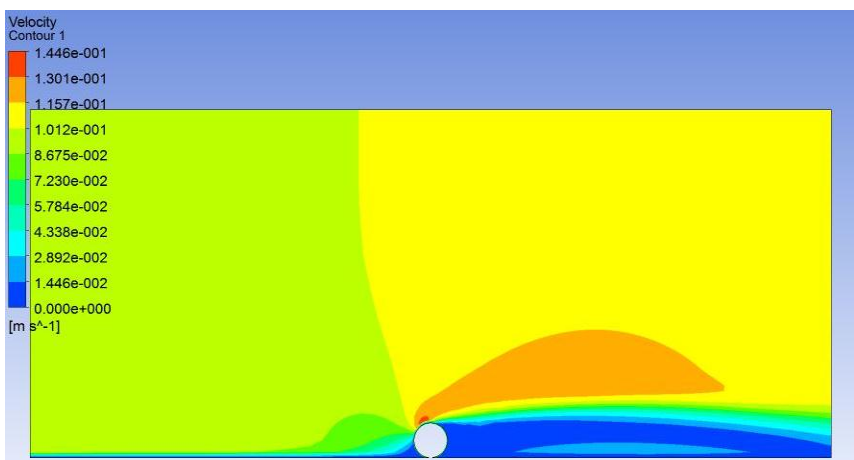

Figure 18. Velocity contour for bare pipe

that uplift is reduced with low spoilers' radial and longitudinal spacing. Low radial and longitudinal spacing seem to have little effect on drag forces.

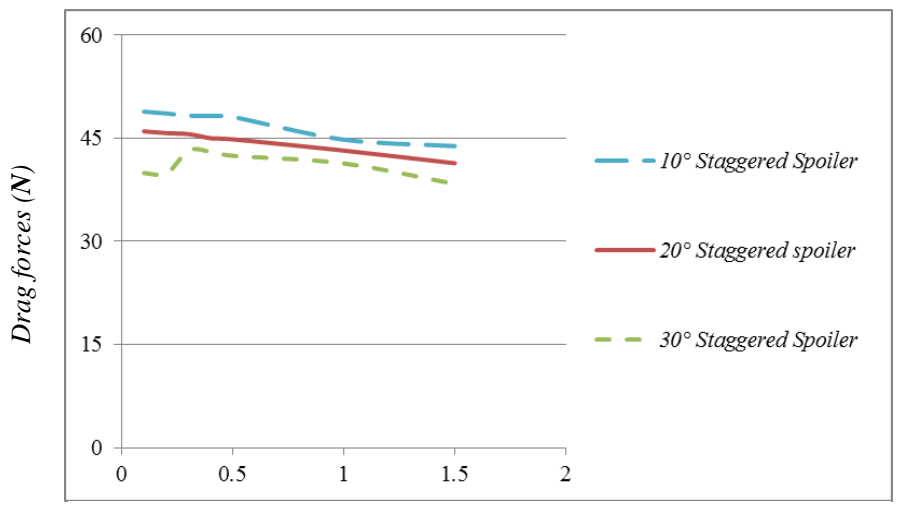

Longitudinal spacing ( $\boldsymbol{m})$

Figure 20.Graph of drag forces as a function of spoiler's angles

preventing it from the fully exposure to the main stream, which tends to move the pipe due to drag and lift forces that can destabilize or break the pipe. 
This has been done through numerical calculations for a wide range of spoilers configurations. As a result, the following conclusions were made from the present study as follows:

- $\quad$ Pipe fitted with staggered spoilers proved to be effective as the flow spoiling around the pipe acted in a way to modify pressures and reduce uplift force.

- The case of staggered $10^{\circ}$ is better than both $20^{\circ}$ and $30^{\circ}$ cases, as it has the lowest $\mathrm{C}_{\mathrm{P}}$ this is beneficial as it indicates less lifting force causing fixation of pipe in place.

- $\quad$ For streamlines in case of staggered spoilers, there is an increase in vortices formation which has its benefit in natural back filling to allow sand re-accumulation around pipeline.

- With the increase of the spoiler's height from $0.25 \mathrm{D}$ to $0.5 \mathrm{D}$ it was noticed that hydrodynamic stresses and downstream vortices decrease and resulting in increased stability of pipeline.

\section{REFERENCES}

[1] Liang, D., Cheng, L., Yeow, K., (2005). Numerical study of the Reynolds-number dependence oftwo-dimensional scour beneath offshore pipelines in steady currents. Ocean Engineering 32 (13),1590-1607.

[2] Liang, D., Cheng, L., (2005). Numerical modeling of flow and scour below a pipeline in currents:Part I. Flow simulation. Coastal Engineering 52 (1), 25-42.

[3] M. P.,Edfeldt.(2006).Submarine pipeline spoiler.Patent US7147402 B2.

[4] Kirkgoz, M.S., Oner, A.A., Akoz, M.S., (2009). Numerical modeling of interaction of a currentwith a circular cylinder near a rigid bed. Advances in Engineering Software 40 (11), 1191-1199.

[5] Zakeri, A. (2010). Estimating Drag Forces on Suspended and Laidon-Seafloor Pipelines Caused by Clay-Rich Submarine Debris Flow Impact. ADVANCES IN NATURAL AND TECHNOLOGICAL HAZARDS RESEARCH 28: 93-104.

[6] Ong, M.C., Utnes, T., Holmedal, L.E., Myrhaug, D., Pettersen, B. (2010). Numerical simulationof flow around a circular cylinder close to a flat seabed at high Reynolds numbers using a $\mathrm{k}-\varepsilon$ model. Coastal Engineering 57 (10), 931-947.

[7] An, H., L. Cheng, et al. (2011). Numerical simulation of a partially buried pipeline in a permeable seabed subject to combined oscillatory flow and steady current. Ocean Engineering 38(10): 1225-1236.

[8] Ibrahim, R. N. F. b. R. A. a. I. (June 2012). Modeling and simulation of vortex induced vibration on the subsea riser/pipeline (GRP pipe). The 4th International Meeting Of Advances In Thermo Fluids (IMAT 2011), Melaka, Malaysia, American Institute of Physics.

[9] Sami Akoz, M. (2012). Investigation of vortical flow characteristics around a partially buried circular cylinder. Ocean Engineering 52: 35 51.

[10] M. Saber. (2013). Numerical simulation of the flow around a subsea pipeline with different protection methods; Journal of Engineering for the Maritime Environment.,Egypt.

[11] Zhu, H., Qi, X., Lin, P., Yang, Y. (2013). Numerical simulation of flow around a submarine pipewith a spoiler and current-induced scour beneath the pipe. Applied Ocean Research 41 (0), 87-100. 